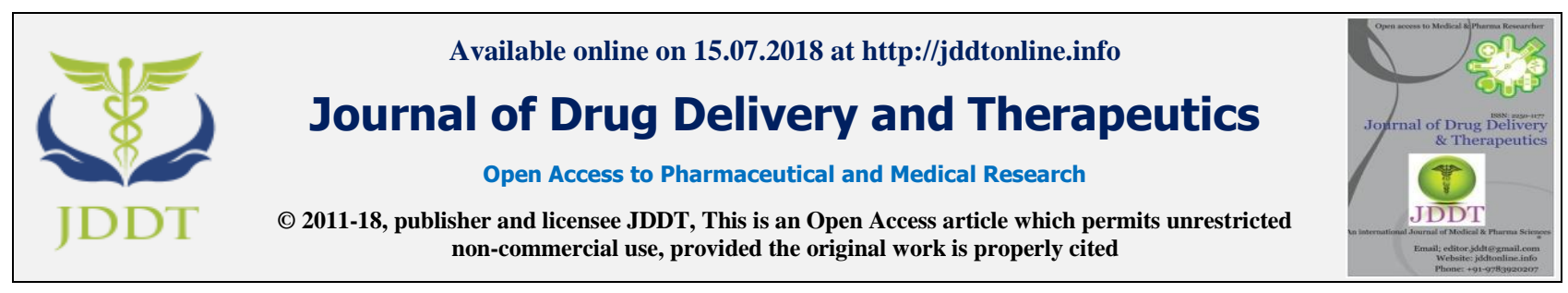

Open $\odot$ Access

Research Article

\title{
FORMULATION AND IN-VITRO EVALUATION OF GASTRO RETENTIVE BILAYER FLOATING TABLET OF FAMOTIDINE HYDROCHLORIDE
}

\author{
Dahima Rashmi *1, Sahare Mithlesh ${ }^{2}$ \\ ${ }^{1}$ School of Pharmacy, Devi AhilyaVishwaVishwavidyalaya, Indore, Madhya Pradesh, India \\ ${ }^{2}$ School of Pharmaceutical Sciences, Rajiv Gandhi Proudyogiki Vishwavidyalaya, Bhopal, Madhya Pradesh, India
}

\section{ABSTRACT}

The present study aims to formulate bilayered tablets of famotidine hydrochloride with a fast release layer using sodium starch glycolate, cross povidone and a sustaining floating layer using polymers like HPMC K100M and HPMC K15M by effervescent approach. The release characteristics were studied on the basis of gel forming polymer, methocel with different concentration of citric acid and sodium bicarbonate. The in vitro buoyancy and floatability were found to be optimum in combination of sodium bicarbonate, citric acid and methocel at concentration of $13 \mathrm{mg}, 6 \mathrm{mg}$ and $90 \mathrm{mg}$ respectively. The drug release from floating tablets was found to be $93.87 \%$ for F1 with methocel K15M. The drug release was sustained for a period of 20-24 hours. When compared different grades of methocel $(\mathrm{K} 100 \mathrm{M}$ and $\mathrm{K} 15 \mathrm{M})$, the methocel $\mathrm{K} 15 \mathrm{M}$ (low viscosity grade) provided better-sustained release characteristics with excellent in vitro buoyancy. The IR study reveals that there is no any possible interaction between drug and excipients used for such formulation. The data from release studies were fitted in different models viz. zero order, first order and Korsemeyer's equation. The result indicated the coupling of swelling and diffusion mechanism so called as Fickian diffusion of famotidine from floating tablets.

Keywords: Bilayered tablets, Fast release layer, Floating layer, Polymers: HPMC, K100M, HPMC K15M, Methocel, Citric acid, Sodium bicarbonate, Famotidine hydrochloride.

Article Info: Received 02 June, 2018; Review Completed 10 July 2018; Accepted 12 July 2018; Available online 15 July 2018

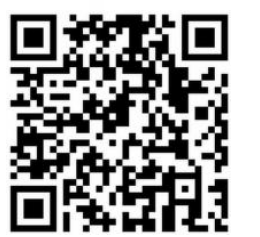

Cite this article as:

Dahima R, Sahare M, Formulation and In-vitro Evaluation of Gastro Retentive Bilayer Floating Tablet of

Famotidine Hydrochloride, Journal of Drug Delivery and Therapeutics. 2018; 8(4):314-319

DOI: http://dx.doi.org/10.22270/jddt.v8i4.1801

*Address for Correspondence:

Dahima Rashmi, School of Pharmacy, Devi AhilyaVishwaVishwavidyalaya, Indore, Madhya Pradesh, India

\section{INTRODUCTION}

Development of oral controlled-release systems has been a challenge to formulation scientists because of their inability to restrain and localize the system in the targeted area of the gastrointestinal tract. Controlled/sustained release preparations using alternative routes have been formulated but the oral route still remains preferable. When the drug is formulated with a gel forming polymer such as semisynthetic derivatives of cellulose, it swells in the gastric fluid with a bulk density less than one. It then remains buoyant and floats in the gastric fluid, affecting a prolonged gastric residence time (GRT).This floating dosage form is well known as a hydrodynamically balanced system (HBS). ${ }^{1-3}$ It has been suggested for the following instances that an active material should be formulated in the form of an HBS to enhance bioavailability: (i) having a dissolution and/or stability problem in the small intestine fluids, (ii) being locally effective in the stomach, (iii) being absorbed only in the stomach and/or upper part of the intestine. ${ }^{4}$ Floating tablets, capsules, beads, microspheres and chambers have been reported in literature.

Famotidine is histamineH2 -receptor antagonist. It is widely prescribed in gastric ulcers, duodenal ulcers, Zollin- ger-Ellison syndrome and gastroesophageal reflux disease. The low bioavailability (40-45\%) and short biological half- life (2.5-4.0 hours) of famotidine following oral administration favors development of a sustained release formulation. The gastroretentive drug delivery systems can be retained in the stomach and assist in improving the oral sustained delivery of drugs that have an absorption window in a particular region of the gastrointestinal tract. These systems help in 
continuously releasing the drug before it reaches the absorption window, thus ensuring optimal bioavailability. ${ }^{6}$ It has been reported that the oral treatment of gastric disorders with an $\mathrm{H}_{2}$ receptor antagonist like famotidine or ranitidine used in combination with antacids promotes local delivery of these drugs to the receptor of parietal cell wall. Local delivery also increases the stomach wall receptor site bioavailability and increases efficacy of drugs to reduce acid secretion. Hence this principle may be applied for improving systemic as well as local delivery of famotidine, which would efficiently reduce gastric acid secretion. $^{7}$

Researchers have developed a single layer floating tablet of famotidine (JAIMINI N TANWAR). In comparison with the single layer tablet, a double layer matrix offers advantages; this formulation of the matrix dosage form with two distinct layers allows separate regulation of drug release kinetics and the floating capabilities to the sustained release second layer. ${ }^{5}$

The multilayered tablet concept has been long utilized to develop sustained release formulations. Such a tablet has a fast releasing layer and may contain bi- or triple layers to sustain the drug release. ${ }^{4}$ The pharmacokinetic advantage relies on the fact that drug release from fast releasing granules leads to a sudden rise in the blood concentration. However, the blood level is maintained at steady state as the drug is released from the sustaining granules.

The present study aims at formulating bilayered tablets of famotidine hydrochloride with a fast release layer using sodium starch glycolate, cross povidone and a sustaining floating layer using polymers like HPMC K100M and HPMC K15M by effervescent approach. The effect of gel-forming polymer methocel on floating properties and release characteristics of famotidine tablets were also evaluated.

\section{MATERIALS AND METHODS}

\section{Materials}

Famotidine was received as a gift sample from Aristo Pharmaceuticals Ltd, Bhopal, India. Methocel K100M (100 cPs apparent viscosity as a $2 \%$ solution) and Methocel K15M (15,000 cPs apparent viscosity as a 2\% solution) were received as gift samples from Colorcon Asia Pvt. Ltd., Goa, India. Magnesium stearate, Hydrochloric acid, Sodium bicarbonate and Citric acid anhydrous were purchased from S.D. Fine Chem Ltd, Ahmedabad, India. Polyvinyl pyrrolidone K-30 (PVP K30) was procured from Ottokemi, Mumbai, India. Lactose and purified Talc were purchased from E. Merck (India) Ltd., Mumbai. All other ingredients were of laboratory grade.

\section{Preparation and characterization of bilayer tablets}

The bilayer tablets of famotidine hydrochloride were prepared by the wet granulation method. The drug and polymers for both fast release and sustaining layer were passed through a respective sieve before their use in the formulation.

\section{Formulation of the fast release layer-}

The dose in the formulation for fast release was $10 \mathrm{mg}$, the maintenance dose or sustained dose $(30 \mathrm{mg})$ of famotidine hydrochloride. The granules were prepared by kneading the intragranular disintegrating agent and excipients and adding water as a binder. Granules screened with an 18 mesh sieve were dried and mixed with excipients. Disintegrating agent could also be added to the granules as extra granular disintegrates, and then mixed with talc and magnesium stearate. The blends was compressed into tablets using flat punch of diameter $8.00 \mathrm{~mm}$ Remiek 12 station mini press tablet machine.

\section{Formulation of the sustained release layer -}

The entire ingredient were weighed accurately and mixed thoroughly. Granulation was done with a solution of PVP K 30 in sufficient alcohol. Granules then passed through sieve (mesh 40) were dried in conventional hot air oven at $45{ }^{\circ} \mathrm{C}$. Drying of the granules was stopped after proper drying. Then dried granules were sized from mesh 40/60 and lubricated with purified talc and magnesium stearate. The blend was compressed into tablet flat punch of diameter $8.00 \mathrm{~mm}$ Remiek 12 station mini press tablet machine.

\section{Characterization of granules:}

Prior to compression, granules were evaluated for their characteristic parameters, such as tapped density, Carr's index and angle of repose. ${ }^{8}$ Carr's compressibility index was calculated from the bulk and tapped densities ${ }^{8}$ using a digital tap density apparatus (Electrolab Ltd, India).

Compression of bilayer tablet-The quantity of granules for the sustained release layer was compressed lightly using a single punch tableting machine (Remiek 12 station mini press tablet machine) equipped with 8 $\mathrm{mm}$ round, flat punches. Over this compressed layer, the required quantity of the fast release layer was placed and compressed to obtain hardness in the range of $4-5 \mathrm{~kg}$ $\mathrm{cm}^{-2}$ to form a bilayer floating tablet.

Physical tests for the bilayer tablets -Standard physical tests for the bilayer matrix tablets were performed (16) and average values were calculated. Mass variation was determined by weighing 20 tablets individually, the average mass was calculated and the percent variation of each tablet was calculated. Hardness was determined by taking 6 tablets from each formulation using a Monsanto hardness tester (Electrolab Pvt. Ltd., India) and the average of pressure $\left(\mathrm{kg} \mathrm{cm}^{-2}\right)$ applied for crushing the tablet was determined. Friability was determined by first weighing 10 tablets after dusting and placing them in a friability tester (Electrolab Pvt. Ltd., India), which was rotated for 4 min at $25 \mathrm{rpm}$. After dusting, the total remaining mass of the tablets was recorded and the percent friability was calculated.

\section{In vitro buoyancy studies}

The in vitro buoyancy was determined by floating lag times according to the method described by Rosa et al. ${ }^{9}$. 
The tablets were placed in a $100-\mathrm{mL}$ beaker containing $0.1 \mathrm{~mol} \mathrm{~L}^{-1} \mathrm{HCl}$. The time required for the tablet to rise to the surface and float was taken as the floating lag time. The experiments were conducted in triplicate.

Drug content uniformity- Twenty tablets were weighed and finely powdered and powder equivalent to average weight was added in $100-\mathrm{mL}$ of $0.1 \mathrm{~N}$ hydrochloric acid, followed by stirring for 30 minutes, the solution was filtered and diluted suitably and the absorbance of resultant solution was measured spectrophotometrically at $266 \mathrm{~nm}$ using $0.1 \mathrm{~N} \mathrm{HCl}$ as blank.

\section{In-vitro Dissolution study}

The release rate of famotidine from immediate release tablets was determined using United State Pharmacopoeia (USP) XXIV dissolution testing apparatus II (paddle method). The dissolution test was performed using $900 \mathrm{ml}$ of $0.1 \mathrm{~N} \mathrm{HCl}(\mathrm{pH}=1.2)$, at 37 $\pm 0.5^{\circ} \mathrm{C}$ and $50 \mathrm{rpm}$. A sample $(5 \mathrm{ml})$ of the solution was withdrawn from the dissolution apparatus at an interval of $0.5,1,2,4,8,12,16,20,22,24$ hours and the samples were replaced with fresh dissolution medium of same quantity. The samples were filtered through a filter. Absorbances of these solutions were measured at 266 $\mathrm{nm}$.

\section{Kinetic analysis of dissolution data}

The rate and mechanism of release of propranolol hydrochloride from the prepared bilayer tablets were analyzed by fitting the dissolution data into the zeroorder equation ${ }^{\mathbf{1 0}}$ :

$$
Q=k_{0} t
$$

Where $Q$ is the amount of drug released at time $t$, and $k$ is the release rate constant, fit - ted to the first order equation (19):

$$
\ln (100-\mathrm{Q})=\ln 100-k_{1} t
$$

Where $k_{1}$ is the release rate constant. The dissolution data was fitted to the Higuchi's equation ${ }^{12}$

$$
Q=k_{2} t^{1 / 2}
$$

Where $k_{2}$ is the diffusion rate constant.

The dissolution data was also fitted to the well known equation (Korsmeyer equation), which is often used to describe the drug release behavior from polymeric systems ${ }^{13}$ :

$$
\log \left(M_{\mathrm{t}} / M_{\infty}\right)=\log k+n \log t
$$

Where $M_{\mathrm{t}}$ is the amount of drug released at time $t, M_{\infty}$ is the amount of drug release after infinite time, $k$ is a release rate constant incorporating structural and geometric characteristics of the tablet and $n$ is the diffusional exponent indicative of the mechanism of drug release.

\section{FT-IR study}

Infrared spectrum was taken (FT-IR, Spectrum RX 1, Perkin Elmer Ltd, Switzerland) by scanning the sample in potassium bromide discs. The samples of pure drug and granules containing different polymers were scanned individually.

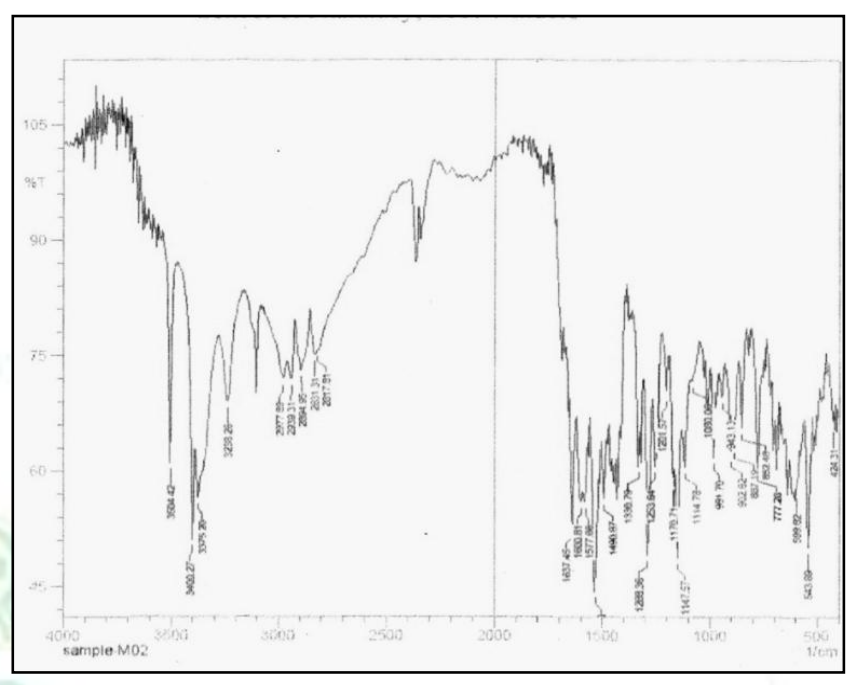

Figure 1: IR Spectra of famotidine and HPMC K100M

\section{RESULTS AND DISCUSSION}

\section{Flow Properties of Granules}

The granules prepared for compression of bilayer floating tablets were evaluated for their flow properties (Table 2). Angle of repose was in the range of 31.23 to 34.02 with granules containing methocel K100M and 32.16 with methocel $\mathrm{K} 15 \mathrm{M}$. Bulk density ranged between 0.46 to $0.57 \mathrm{gm} / \mathrm{cm}^{3}$ with granules containing methocel $\mathrm{K} 100 \mathrm{M}$ and $0.46 \mathrm{gm} / \mathrm{cm}^{3}$ with methocel K15M. Tapped density ranged between 0.54 to $0.68 \mathrm{gm} / \mathrm{cm}^{3}$ with granules containing methocel K100M and $0.53 \mathrm{gm} / \mathrm{cm}^{3}$ with methocel $\mathrm{K} 15 \mathrm{M}$. Hausner's ratio ranged from 1.1 to 1.2 for granules of different formulations. These values indicate that the prepared granules exhibited good flow properties.

Table 1: Optimization of fast release layer

\begin{tabular}{|l|c|c|c|c|c|c|}
\hline $\begin{array}{c}\text { BATCH CODE } \longrightarrow \\
\text { INGREDIENT*1 }\end{array}$ & A1 & A2 & A3 & A4 & A5 & A6 \\
\hline FAMOTIDINE & 10 & 10 & 10 & 10 & 10 & 10 \\
\hline POVIDONE & 2 & 3 & 4 & - & - & - \\
\hline SSG & - & - & - & 2 & 4 & 6 \\
\hline DCP & 85 & 84 & 83 & 85 & 83 & 81 \\
\hline TALC & 2 & 2 & 2 & 2 & 2 & 2 \\
\hline MG STEATARTE & 1 & 1 & 1 & 1 & 1 & 1 \\
\hline TOTAL & 100 & 100 & 100 & 100 & 100 & 100 \\
\hline \multicolumn{7}{|l}{ *All the ingredient in mg } \\
\hline
\end{tabular}


Table 2: Optimization of Sustained release layer

\begin{tabular}{|l|c|c|c|c|l|l|l|c|}
\hline $\begin{array}{c}\text { Batch code } \\
\text { Ingredients* }\end{array}$ & F1 & F2 & F3 & F4 & F5 & F6 & F7 & F8 \\
\hline Famotidine & 30 & 30 & 30 & 30 & 30 & 30 & 30 & 30 \\
\hline HPMC K 15 M & 40 & - & - & - & - & - & - & - \\
\hline HPMC K 100 M & - & 40 & 30 & 60 & 50 & 40 & 40 & 40 \\
\hline Sodium bi carbonate & 12 & 12 & 12 & 12 & 12 & 13 & 13 & 13 \\
\hline Citric acid & 6 & 6 & 6 & 6 & 6 & 6 & 5 & 3.75 \\
\hline Lactose & 20 & 20 & 20 & 20 & 20 & 24 & 24 & 24 \\
\hline Talc & 1 & 1 & 1 & 1 & 1 & 1 & 1 & 1 \\
\hline Magnesium stearate & 1 & 1 & 1 & 1 & 1 & 1 & 1 & 1 \\
\hline $\begin{array}{l}\text { Floating lag time } \\
\text { (Seconds) }\end{array}$ & 42 & 44 & 39 & 60 & 51 & 44 & 52 & 70 \\
\hline
\end{tabular}

Table 3: Characterization of powder of floating layer

\begin{tabular}{|c|c|c|c|c|c|c|c|c|}
\hline Parameters & F1 & $\mathrm{F} 2$ & F3 & F4 & F5 & F6 & F7 & F8 \\
\hline Bulk density $(\mathrm{g} / \mathrm{cc})$ & 0.46 & 0.46 & 0.47 & 0.57 & 0.48 & 0.54 & 0.51 & 0.47 \\
\hline Tapped density (g/cc) & 0.53 & 0.54 & 0.55 & 0.68 & 0.58 & 0.65 & 0.61 & 0.56 \\
\hline Compressibility index (\%) & 13.20 & 14.81 & 14.5 & 16.1 & 17.2 & 16.9 & 16.3 & 19.1 \\
\hline Hausner ratio & 1.15 & 1.17 & 1.17 & 1.19 & 1.2 & 1.2 & 1.1 & 1.19 \\
\hline Angle of repose $(\varnothing)$ & 32.16 & 34.02 & 33.34 & 33.21 & 33.56 & 32.75 & 33.03 & 31.23 \\
\hline$\%$ Weight variation & 4.5 & 4.7 & 4.7 & 4.4 & 4.8 & 4.8 & 4.5 & 4.6 \\
\hline$\%$ Friability & 0.11 & 0.13 & 0.12 & 0.11 & 0.12 & 0.11 & 0.12 & 0.12 \\
\hline$\%$ Drug content & 98.55 & 98.74 & 99.05 & 98.66 & 98.80 & 98.52 & 99.12 & 98.76 \\
\hline
\end{tabular}

\section{FT-IR study}

The FT-IR spectrum of famotidine hydrochloride and HPMC K100M, shown in Fig. 1, revealed the presence of peaks at $3399.89 \mathrm{~cm}^{-1}$ due to the asymmetrical N-H stretching, peaks at $1658.48 \mathrm{~cm}^{-1}$ due to the $\mathrm{C}=\mathrm{C}$ stretching, symmetrical $\mathrm{N}-\mathrm{H}$ stretching band at 3376.75 $\mathrm{cm}^{-1}$ and the peak at $1638.00 \mathrm{~cm}^{-1}$ was due to a $\mathrm{C}=\mathrm{N}$ stretching. Major frequencies of functional groups of pure drug remain intact in granules containing polymers; hence, there is no major interaction between the drug and polymers used in the study.

\section{Evaluation of Floating Tablets}

The bilayer floating tablets of famotidine were prepared by effervescent technique using methocel (K100M, K15M), sodium bicarbonate, citric acid and PVP K-30. The magnesium stearate and talc were used as lubricant and glidant, respectively. The results of the physicochemical characterization are shown in Table 3. The weight of the tablet varied between $200 \mathrm{mg}$ to 230 $\mathrm{mg}$ for different formulations with low standard deviation values, indicating uniformity of weight. The variation in weight was within the range of $\pm 5 \%$ complying with pharmacopoeial specifications. ${ }^{\mathbf{5}}$ The hardness for different formulations was found to be between 4.05 to $5.25 \mathrm{~kg} / \mathrm{cm} 2$ indicating satisfactory mechanical strength. The friability was below $1 \%$ for all the formulations, which is an indication of good mechanical resistance of the tablet. The drug content varied between 39.26 to $39.92 \mathrm{mg}$ in different formulations with low coefficient of variation (C.V. < $1.0 \%$ ), indicating content uniformity in the prepared batches. All the tablets were prepared by effervescent approach. Sodium bicarbonate was added as a gasgenerating agent. Sodium bicarbonate induced carbon dioxide generation in presence of dissolution medium (0.1 N hydrochloric acid).

The combination of sodium bicarbonate and citric acid provided desired floating ability and therefore this combination was selected for the formulation of the floating tablets. It was observed that the gas generated is trapped and protected within the gel, formed by hydration of polymer (methocel), thus decreasing the density of the tablet below 1 and tablet becomes buoyant. The tablet swelled radially and axially during in vitro buoyancy studies. The concentration of gasgenerating agent affected the floating lag time, as the amount of gas-generating agent was increased, the floating lag time decreased. The incorporation of gasgenerating agent exhibits reduction the in floating lag time. Due to high solubility of drug there was no effect observed on release pattern.

All the batches of tablets were found to exhibit short floating lag times due to presence of sodium bicarbonate and citric acid. Decrease in the citric acid level increased the floating lag time and tablets were found to float for longer duration. The tablets with low-viscosity grade methocel $\mathrm{K} 15 \mathrm{M}$ or low concentration of polymer exhibited short floating lag time and floated for longer duration as compared with formulations containing high-viscosity grade methocel K100M or high concentration of polymer. This indicated that the molecular weight distribution or viscosity of the gel- 
forming polymer methocel influenced the in vitro buoyancy.

Reduction in methocel level in the formulations F4, F5, and F9, F10 prolonged the floating lag time and shortened the total floating time. Thus a combination of sodium bicarbonate $(13 \mathrm{mg})$ and citric acid $(6 \mathrm{mg})$ with methocel $(90 \mathrm{mg}$ ) was found to achieve optimum in vitro buoyancy and floatability.

The $\mathrm{pH}$ of the stomach is elevated under fed condition $(\sim 3.5)$, therefore citric acid was incorporated in the formulation to provide an acidic medium for sodium bicarbonate; more over citric acid has an stabilizing effect on famotidine formulation. The effect of methocel in the tablet with varying proportion of citric acid and sodium bicarbonate was studied on the release characteristics.

It is evident from the in vitro dissolution data that increase in citric acid concentration increased the release rate but reduced the floating time, probably due to of excess carbon dioxide, disturbing the monolithic tablet. The citric acid level in the formulations greatly influenced the drug release, irrespective of methocel grade.

The drug release from floating tablets was found to be $93.87 \%$ for $\mathrm{F} 1$ with methocel $\mathrm{K} 15 \mathrm{M}$. The drug release for formulations containing high-viscosity grade methocel K100M (F2 to F8) varied between 84.41 to $94.83 \%$.
The prepared formulations sustained the drug release for a period of 20-24 hours. Comparing the two different grades of methocel (K100M and $\mathrm{K} 15 \mathrm{M})$, it was found that low-viscosity grade methocel $\mathrm{K} 15 \mathrm{M}$ provided better-sustained release characteristics with excellent in vitro buoyancy. Formulations containing sodium bicarbonate and citric acid in ratio of 13:1 with varying amount of methocel were studied for their effect on release profile of famotidine. It was observed that the release of famotidine from such formulations increased on decreasing the proportion of methocel in the formulation but duration of floating decreased.

The data obtained from in vitro dissolution studies were fitted in different models viz. zero order, first order and Korsemeyer's equation (Table 4). As clearly indicated in table 4 , the correlation coefficient value of all the formulations showed that the formulations did not follow zero order release pattern but batch F2 and F6 shows fair zero order. When the data were plotted according to the first order equation, the formulations show a fair linearity, with correlation coefficient values between 0.9509-0.9848. To explore the release pattern, results of the in-vitro dissolution data were fitted to the Korsmeyer equation, which characterizes the transport mechanism. Regression analysis was performed and regression values ' $\mathrm{r}$ ', were 0.9038 to 0.9915 for different formulations. Slope values $(0.5<\mathrm{n}<1.0)$ of 0.37 indicates the coupling of swelling and diffusion mechanism so called as Fickian diffusion of famotidine from floating tablets.

Table 4: Kinetic treatment of dissolution data of famotidine hydrochloride

\begin{tabular}{|c|c|c|c|c|}
\hline \multirow{2}{*}{ Formulation code } & \multicolumn{3}{|c|}{ Correlation coefficient $\left(\mathrm{r}^{2}\right)$} & \multirow{2}{*}{$\begin{array}{c}\text { Peppas release } \\
\text { exponent }(\mathrm{n})\end{array}$} \\
\cline { 2 - 4 } & Zero order & First order & Higuchi's type & 0.9459 \\
\hline F1 & 0.8518 & 0.9848 & 0.9492 & 0.8619 \\
\hline F2 & 0.957 & 0.9591 & 0.9855 & 0.9399 \\
\hline F3 & 0.9129 & 0.8159 & 0.9038 & 0.9635 \\
\hline F4 & 0.9105 & 0.9653 & 0.9823 & 0.9313 \\
\hline F5 & 0.8815 & 0.9842 & 0.9672 & 0.9945 \\
\hline F6 & 0.9498 & 0.9509 & 0.9915 & 0.9895 \\
\hline F7 & 0.8365 & 0.9813 & 0.9769 & 0.9909 \\
\hline F8 & 0.8285 & 0.9757 & 0.974 & \\
\hline
\end{tabular}

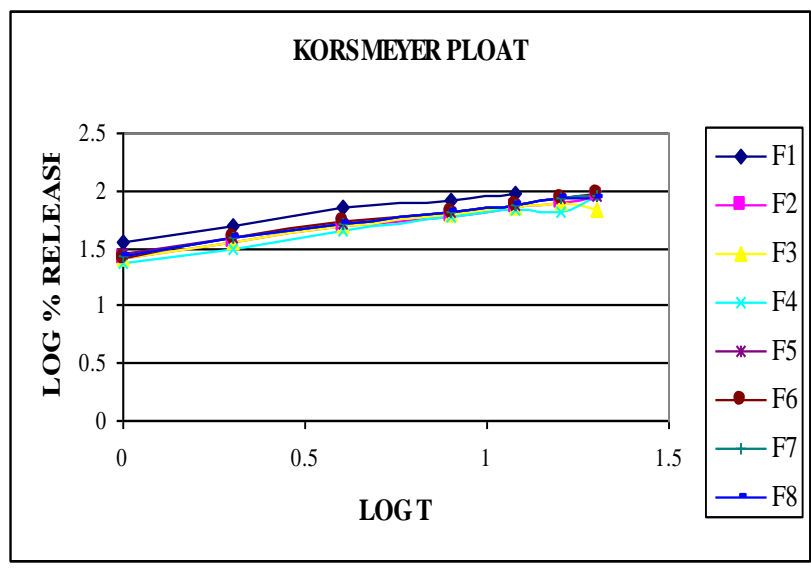

Figure 2: Kinetic analysis of dissolution data (Korsmeyer equation)

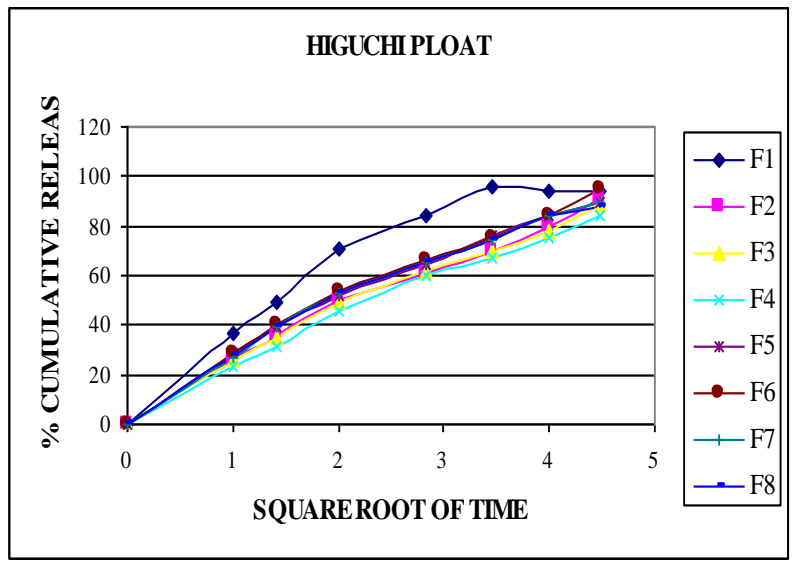

Figure 3: Kinetic analysis of dissolution data (Higuchi Plot) 


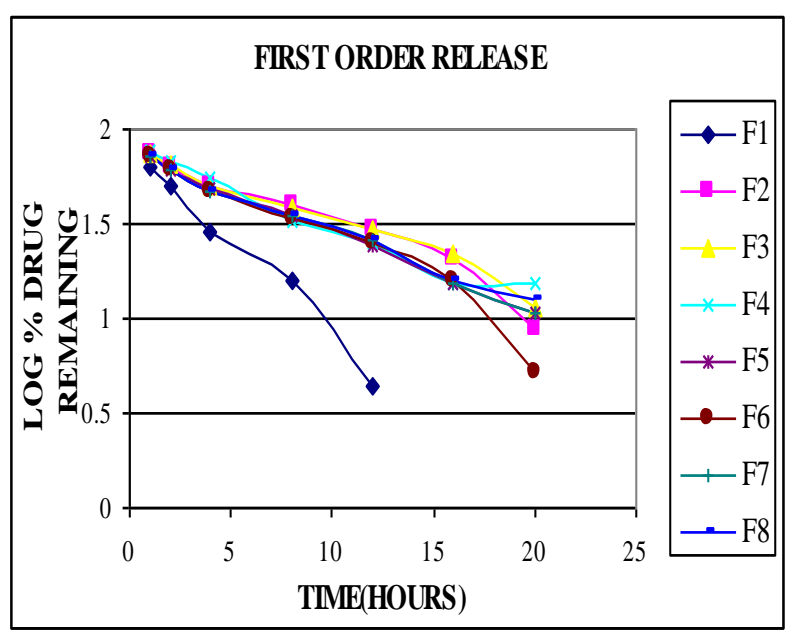

Figure 4: Kinetic analysis of dissolution data (First order Release)

\section{CONCLUSION}

Oral solid dosage form based on bilayer floating drug delivery is promising to achieve bimodal drug release. After an immediate drug release from first layer, controlled release can be achieved from second layer in an area that could maximize drug reaching its absorption site. The addition of gel-forming polymer methocel (K100M and $\mathrm{K} 15 \mathrm{M}$ ) and gas-generating agent sodium bicarbonate along with citric acid was essential to achieve in vitro buoyancy. The drug release from the tablets was sufficiently sustained and Fickian transport of the drug from tablets was confirmed.

This system can be useful for pharmaceuticals following chronopharmacology and having limited physiological stability and absorption window in upper part of GI tract. However, further clinical studies are needed to explore potential of system for antibiotics.

\section{REFERENCES}

1. Sheth PR, Tossounian JL, The hydrodynamic balanced system (HBS): A novel drug delivery system for oral use, Drug Dev. Ind. Pharm. 1984; 10:313-339.

2. Chien YE, Potential developments, new approaches in oral controlled release drug delivery systems, Drug Dev. Ind. Pharm. 1993; 9:486-488.

3. Deshpande AA, Rhodes CT, Shah NH, Malick AW, Controlled release drug delivery systems for prolonged gastric residence: an overview, Drug Dev. Ind. Pharm. 1996; 22:531-539.

4. Uzdemir N, Rdu SO, Ozkan Y, Studies of floating dosage forms of furosemide: in vitro and in vivo evaluation of bilayer tablet formulations, Drug Dev. Ind. Pharm. 2000; 26:857866.

5. Ingani HM, Timmermans J, Moes AJ. Conception and in vivo investigation of peroral sustained release floating dosage forms with enhanced gastrointestinal transit, Int. J. Pharm. 1987; 35:157-164.

6. Singh B; Kim K.J. Control. Release, 2000; 63:235-59.

7. Coffin M; Parr A. US Patent 5407 687, April 18, 1995.

8. Reynolds, J.E.F. Martindale The Extra Pharmacopoeia, The Royal Pharmaceutical Society: London, 1996, pp.1218-20.

9. Rosa M, Zia H, Rhodes T. Dosing and testing in-vitro of a bioadhesive and floating drug delivery system for oral application. Int J Pharm. 1994; 105:65-70.

10. Merchant HA, Shoaib HM, Tazeen J, Yousuf RI, Once-daily tablet formulation and in vitro release evaluation of cefpodoxime using hydroxypropyl methylcellulose: A technical note, AAPS Pharm. Sci. Tech. 2006; 7:78; DOI: 10.1028/pt 070378.

11. Bourne DW, Pharmacokinetics,inModern Pharmaceutics,4th ed. (Eds. G. S. Banker and C. T. Rhodes), Marcel Dekker, New York 2002, pp. 67-92.

12. Higuchi T, Mechanism of sustained action medication, $J$. Pharm. Sci. 1963; 52:1145-1149.

13. Korsmeyer RW, Gurny R, Docler E, Buri P, Peppas NA, Mechanism of solute release from porous hydrophilic polymers, Int. J. Pharm. 1983; 15:25-35; DOI: 10.1016/0378-5173(83) 90064-9. 